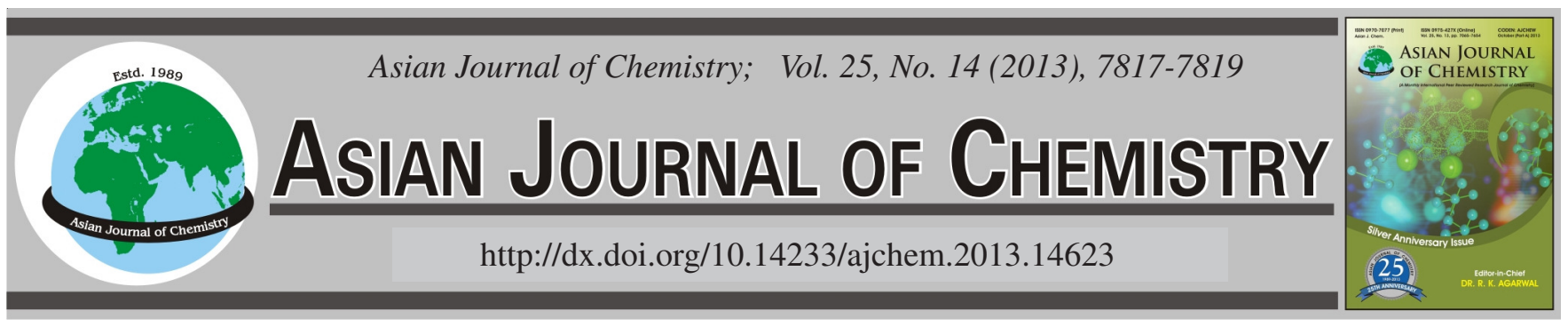

\title{
Synthesis and Characteristics of Al(III)-Imprinted Silica Gel Sorbent
}

Lan-Lan Ding*, Zhi-Jing Zhong, Su-Qun Long, Yi Deng, Yong-Qing Hui, Tao Lin, Xiao-Bo He and Yin-Hang Zhou

Institute of Nuclear Physics and Chemistry, China Academy of Engineering Physics, Mianyang 621900, Sichuan Province, P.R. China

*Corresponding author: E-mail: hinatading@gmail.com

(Received: 28 September 2012;

Accepted: 18 July 2013)

AJC-13816

\begin{abstract}
In this study, a new $\mathrm{Al}(\mathrm{III})$-imprinted silica gel sorbent was synthesized by a surface imprinting techniquefor selective extraction or preconcentration of $\mathrm{Al}(\mathrm{III})$. Compared with non-imprinted polymer particles, the aluminium ion-imprinted silica gel (Al-IIISG) had higher selectivity and adsorption capacity for $\mathrm{Al}(\mathrm{III})$. The maximum static adsorption capacity of the aluminium ion-imprinted silica gel for $\mathrm{Al}(\mathrm{III})$ was $12.79 \mathrm{mg} / \mathrm{g}$. Results suggested that aluminium ion-imprinted silica gel was a material of efficient, low-cost for $\mathrm{Al}(\mathrm{III})$ separation and concentration.
\end{abstract}

Key Words: Imprinted silica gel sorbent, Static adsorption capacity, Separation and concentration.

\section{INTRODUCTION}

Molecular imprinting technology is an efficient method to produce functionalized materials that so far there are a lot of metal ions imprinted polymers have been prepared, including $\mathrm{Cu}(\mathrm{II})^{1}, \mathrm{Hg}(\mathrm{II})^{2}, \mathrm{UO}_{2}(\mathrm{VI})^{3}, \mathrm{Ni}(\mathrm{II})^{4}, \mathrm{~Pa}(\mathrm{II})^{5}, \mathrm{Pd}(\mathrm{III})^{6}, \mathrm{Zn}(\mathrm{II})^{7}$, $\mathrm{Cd}(\mathrm{II})^{8}$ and $\mathrm{Cs}(\mathrm{I})^{9}$ imprinted polymers. A new method using $\mathrm{Al}(\mathrm{III})$-imprinted sorbent for preconcentration trace aluminium in solution samples prior to its determination by flame atomic absorption spectrometry was established. This method presented high selectivity and adsorption capacity for $\mathrm{Al}$ (III) and possessed simple, convenient and acurate characteristics.

\section{EXPERIMENTAL}

Reagents of analytical and spectral purity were used for all experiments and doubly distilled deionized water was used throughout. Standard stock solutions of $\mathrm{Al}(\mathrm{III})$ was prepared by dissolving analysis pure-grade $\mathrm{Al}_{2}\left(\mathrm{SO}_{4}\right)_{3} \cdot 18 \mathrm{H}_{2} \mathrm{O}$ (Chengdu Lianhe Chemical Company, Chengdu, China). Silica gel (60100 mesh, Chemical Company of National Medicine, China) and $\gamma$-aminopropyltrimethoxy silane (APS, Nanjing Liangui Chemical Company, China) were used to prepare the ionimprinted and non-imprinted functional silica gel sorbent.

The silica gel surfaces were activated by refluxing silica (60-100 mesh) with 1:1 hydrochloric acid under stirring for $4 \mathrm{~h}$, then the activated silica gel was filtered and washed with doubly distilled water to neutral and dried under vacum at $80^{\circ} \mathrm{C}$ for $12 \mathrm{~h} . \mathrm{Al}_{2}\left(\mathrm{SO}_{4}\right)_{3} \cdot 18 \mathrm{H}_{2} \mathrm{O}$ was dissolved in $80 \mathrm{~mL}$ methanol under stirring and heating, then $4 \mathrm{~mL} \gamma$-aminopropyltrimethoxy silane was added into the mixture. The solution was stirred and refluxed for $2 \mathrm{~h}$, then $4 \mathrm{~mL}$ TEOS was added into the mixture and the solution was stirred and heated for $24 \mathrm{~h}$. The product was washed by ethanol to remove the reactionless $\gamma$-aminopropyltrimethoxy silane and TEOS. Then 1:1 hydrochloride acid was added to remove metal ions from the polymer. The final product was filtered, washed with doubly distilled water to neutral and dried under vacuum at $68^{\circ} \mathrm{C}$ for $16 \mathrm{~h}$.

Flame atomic absorption spectrometry measurements were carried out on a Zeenit $700 \mathrm{p}$ spectrometer (Analytik jena, Germany) wit an air/acetylene flame. The instrumental parameters were optimized in order to obtain maximum signal-to-noise ratio. Infrared spectra of the imprinted and nonimprinted absorbent were performed with a Fourier transform infrared (FT-IR) spectrometer (Nicolet6700, American). Chemical bonding information was obtained by Raman spectrometer. The Raman spectrometer(Nicolet DXR, American).

\section{RESULTS AND DISCUSSION}

Adsorption experiments and selectivity studies: The adsorption capacity of $\mathrm{Al}(\mathrm{III})$ on ion-imprinted and nonimprinted silica gel sorbent were investigated by static adsorption study. It was performed by mix $0.1 \mathrm{~g}$ absorbents (imprinted and non-imprinted) with $\mathrm{Al}$ (III) ion solution in the concentration range $10-200 \mathrm{mg} / \mathrm{L}(\mathrm{pH}-6)$ for $0.5 \mathrm{~h}$. The $\mathrm{pH}$ of solution was adjusted to desired values by adding hydrochloric acid as buffer. At the end of predetermined time intervals the polymers was separated by centrifugation. The selected metal ions $\mathrm{Cr}$ (III) was added to solutions to prove the competitive adsorption. Under the conditions of optimum initial concen- 
tration of Al(III), $0.1 \mathrm{~g}$ each of individual inorganic species were added to solutions and the absorbed amount of these elements were ascertained by flame atomic absorption spectrometry.

The adsorption capacity, distribution ratio, selectivity factor of $\mathrm{Al}(\mathrm{III})$ with respect to $\mathrm{Cr}(\mathrm{III})$ and relative selectivity factor were calculated using following equations:

$$
\begin{gathered}
Q_{e}=\frac{\left(C_{o}-C_{e}\right) V}{W} \\
D=\frac{Q_{e}}{C_{e}} \\
S=\frac{D_{A l}}{D_{M}} \\
S_{r}=\frac{S_{i}}{S_{n}} \\
E=\left(C_{0}-C_{e}\right) / C_{0} \times 100 \%
\end{gathered}
$$

where, $\mathrm{Q}_{\mathrm{e}}$ represents the adsorption capacity $(\mathrm{mg} / \mathrm{g}), \mathrm{C}_{\mathrm{o}}$ and $\mathrm{C}_{\mathrm{e}}$ the initial and equilibrium concentrations of $\mathrm{Al}(\mathrm{III})(\mathrm{mg} / \mathrm{L})$, $\mathrm{W}$ the mass of polymer $(\mathrm{g}), \mathrm{V}$ the volume of methods ion solutions (L), D the distribution ratio $(\mathrm{L} / \mathrm{g}), \mathrm{S}$ the selectivity factor, $\mathrm{D}_{\mathrm{Al}}$ and $\mathrm{D}_{\mathrm{m}}$ represent the distribution ratio of $\mathrm{Al}(\mathrm{III})$ and $\mathrm{Cr}(\mathrm{III}), \mathrm{S}_{\mathrm{r}}$ the relative selectivity factor, $\mathrm{D}_{\mathrm{i}}, \mathrm{D}_{\mathrm{n}}$ and $\mathrm{S}_{\mathrm{i}}, \mathrm{S}_{\mathrm{n}}$ represent the distribution ratios and selectivity factors of imprinted and non-imprinted silica gel sorbent, respectively.

IR analysis: To ascertain the presence of useful chemical bond in $\mathrm{Al}(\mathrm{III})$-imprinted chloride-functionalized silica gel sorbent, FT-IR spectra were obtained from non-imprinted, imprinted and adsorptive silica gel sorbents. As showed in Fig. 1 , the observed features aroud $1090 \mathrm{~cm}^{-1}$ and $958 \mathrm{~cm}^{-1}$ indicated $\mathrm{Si}-\mathrm{O}-\mathrm{Si}$ and $\mathrm{Si}-\mathrm{O}-\mathrm{H}$ stretching vibration, respectively. The presence of adsorption water was reflected by $v(\mathrm{OH})$ vibration at $3429 \mathrm{~cm}^{-1}$ and $1636 \mathrm{~cm}^{-1}$. The bands around 800 $\mathrm{cm}^{-1}$ and $472 \mathrm{~cm}^{-1}$ resulted from $\mathrm{Si}-\mathrm{O}$ symmetrical and anisomerous vibrations. Imprinted and non-imprinted sorbent showed a very similar location and appearance of the major bands.

Raman spectra: The structural and chemical properties of the ion-imprinted and non-imprinted functional silica gel sorbent was probed by means of Raman studies. Fig. 2 shows the Raman spectra of ion-imprinted and non-imprinted functional silica gel sorbent samples. The absence of sharp and well-defined peaks suggests local structural disorder of the prepared films.

Adsorption capacity of Al(III)-imprinted sorbent for Al(III): The adsorption capacity is an important factor to evaluate the $\mathrm{Al}$ (III)-imprinted sorbent. In order to investigate the adsorption capacity of $\mathrm{Al}(\mathrm{III})$ on imprinted and nonimprinted polymer particles, $0.1 \mathrm{~g}$ of polymer particles was introduced into a solution of $\mathrm{Al}(\mathrm{III})$. As showed in Fig. 3, the adsorption capacity of imprinted silica gel sorbents increases with the increased initial concentration and the highest adsorption capacity could achieve $12.79 \mathrm{mg} / \mathrm{g}$ with saturation state, when the non-imprinted silica gel sorbents could only reach $4.21 \mathrm{mg} / \mathrm{g}$ around. The adsorption capacity for imprinted particles is higher than for non-imprinted particles at all initial concentrations of aluminium because in imprinted particles the cavities created after removal of template is complementary to the imprinted ion in size and coordination geometries, wheras in non-imprinted particles there is a random distribution of ligand functionalities.
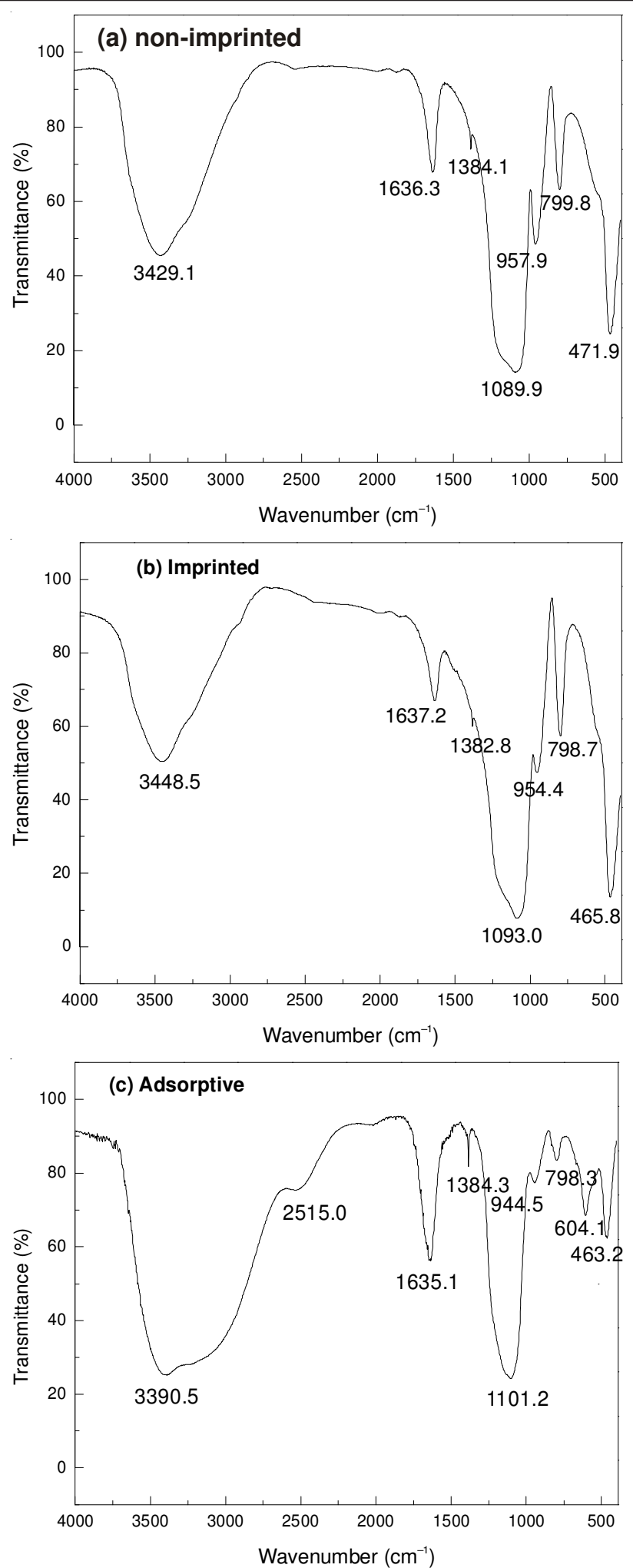

Fig. 1. FT-IR spectra of the non-imprinted, imprinted and adsorptive silica gel sorbents

Effect of coexisting ions: The effects of coexisting ions on the adsorption of $\mathrm{Al}(\mathrm{III})$ in imprinted sorbent were investigated. The results of competitive adsorption of $\mathrm{Cr}$ (III)/Al(III) were showed in Table-1. The tolerance of the coexisting ions, defined as the largest amount making the recovery of the studied elements less than $90 \%$. Results showed that up to $\mathrm{mg} / \mathrm{L}$ of $\mathrm{Zn}(\mathrm{III}), \mathrm{mg} / \mathrm{L}$ of $\mathrm{Ni}(\mathrm{III})$ had no significant interference on 
TABLE-1

DISTRIBUTION RATIOS, SELECTIVITY FACTOR AND SELECTIVITY COEFFICIENT OF IMPRINTED SILICA GEL SORBENTS

\begin{tabular}{|c|c|c|c|c|c|c|c|c|}
\hline \multirow{2}{*}{ Sorbents } & \multicolumn{2}{|c|}{ Initial Concentration } & \multicolumn{2}{|c|}{ Adsorption Rate } & \multicolumn{2}{|c|}{ Adsorption capacity } & \multicolumn{2}{|c|}{$\mathrm{Sr}$} \\
\hline & $\mathrm{Al}(\mathrm{III})$ & $\mathrm{Cr}(\mathrm{III})$ & $\mathrm{Al}(\mathrm{III})$ & $\mathrm{Cr}(\mathrm{III})$ & $\mathrm{Al}(\mathrm{III})$ & $\mathrm{Cr}(\mathrm{III})$ & $\mathrm{Al}(\mathrm{III})$ & $\mathrm{Cr}(\mathrm{III})$ \\
\hline \multirow{2}{*}{ Imprinted } & 1 & 0 & 99.9 & - & 1.665 & - & - & - \\
\hline & 1 & 1 & 99.6 & 65.4 & 1.593 & 0.627 & 21.5 & 6.72 \\
\hline Non- & 1 & 0 & 98.7 & - & 1.645 & - & - & - \\
\hline imprinted & 1 & 1 & 95.3 & 86.4 & 1.588 & 1.434 & 3.2 & - \\
\hline
\end{tabular}
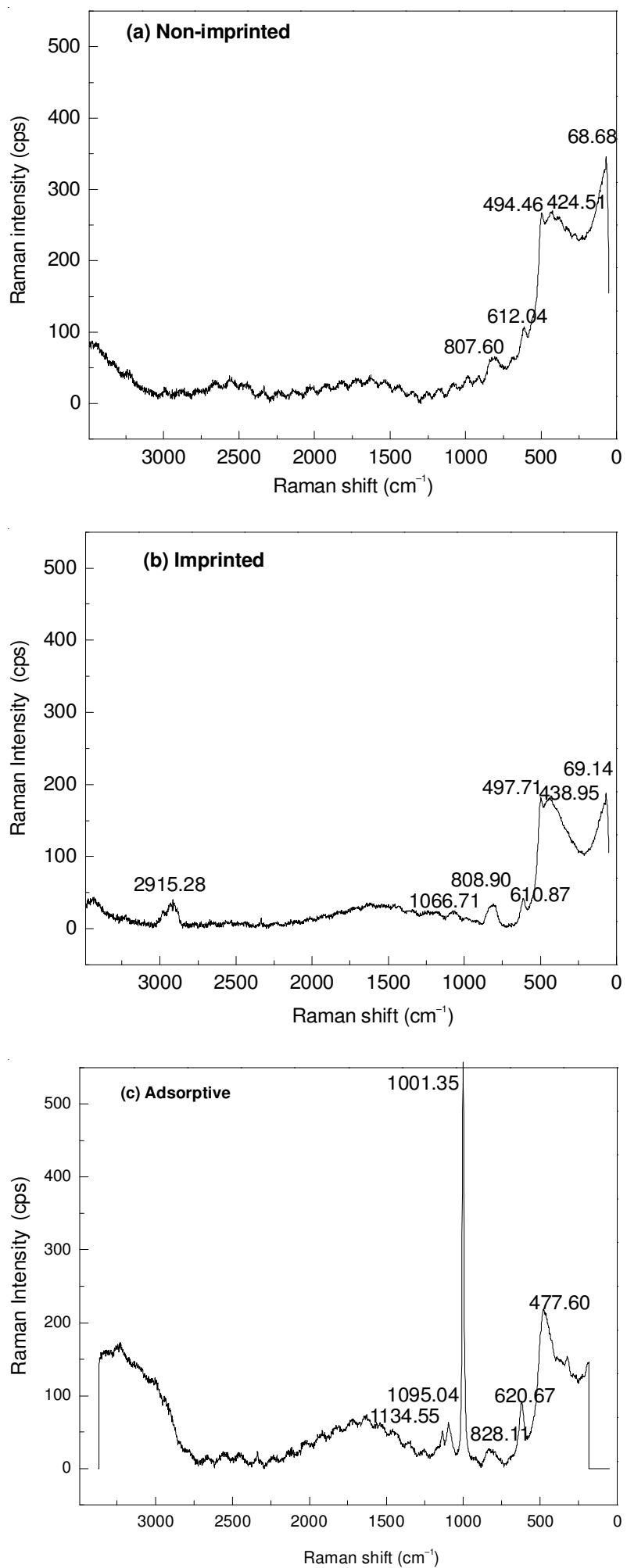

Fig. 2. Raman spectra of the activated, imprinted and non-imprinted silica gel sorbents

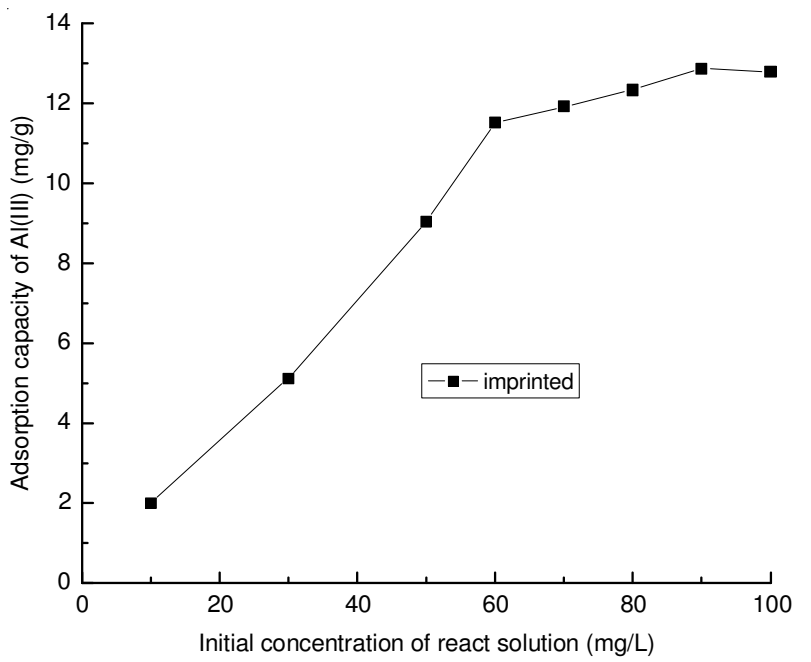

Fig. 3. Effect of concentration on the adsorption of $\mathrm{Al}(\mathrm{III})$ on imprinted silica gel sorbents

determination under the Selectivity conditions, which shows that Al(III)-imprinted silica gel sorbent has a good selectivity for $\mathrm{Al}(\mathrm{III})$.

\section{Conclusion}

In this work, a selective and sensitive method for determination of cooper was used by a new type of $\mathrm{Al}(\mathrm{III})$-imprinted silica gel sorbent. The preparation of was relatively simple and rapid. The ion-imprinted sorbent had high adsorption capacity and selectivity for $\mathrm{Al}(\mathrm{III})$. The maximum adsorption capacity of $\mathrm{Al}(\mathrm{III})$ on ion-imprinted silica gel sorbent was 12.79 $\mathrm{mg} / \mathrm{g}$. Competitive adsorption studies showed that Al(III)imprinted silica gel sorbent offer the advantage of selectivity towards $\mathrm{Al}(\mathrm{III})$ ion in the presence of $\mathrm{Cr}(\mathrm{III})$ ions.

\section{ACKNOWLEDGEMENTS}

This work was supported by the Engineering Physics Foundation (No. 2011B0302046 and No. 2010B0302034).

\section{REFERENCES}

1. L.-L. Ding, S.-Q. Long, Y.-H. Zhou and Y. Deng, Asian J. Chem., 24, 10 (2012).

2. I. Dakova, I. Karadjova, V. Georgieva and G. Georgiev, Talanta, 78, 523 (2009).

3. D.K. Singh and S. Mishra, Anal. Chim. Acta, 644, 42 (2009).

4. A. Ersoz, R. Say and A. Denizli, Anal. Chim. Acta, 502, 91 (2004).

5. C. Esen, M.E. Andac, N. Bereli, R. Say, E. Henden and A. Denizli, J. Mater. Sci. Eng. C, 29, 2464 (2009).

6. B. Godlewska-zykiewicz, B. Lesniewska and I. Wawreniuk, Talanta, 83, 596 (2010).

7. J.C. Zhao, B. Han, Y.F. Zhang and D.D. Wang, Anal. Chim. Acta, 603, 87 (2007).

8. D.K. Singh and S. Mishra, J. Hazard. Mater, 164, 1547 (2009).

9. Z.L. Zhang, X.H. Xu and Y.S. Yan, Desalination, 263, 97 (2010). 